\title{
Compliance Promotion for the Rehabilitation of Children with Intellectual Disabilities: An Intervention Proposal for Parents
}

\author{
Zampino Anna*, Rosano Mariagrazia, Scaduto Luisa, Murdaca Anna Maria \\ Department of Human and Social Sciences, University of Messina, Messina, 98100, Italy
}

\begin{abstract}
This paper describes a research aimed at implementing a training program to promote compliance during the rehabilitation intervention in parents of children with intellectual disabilities. The training involved 10 pairs of parents with children between 1 and 8 years of age. The goal was to encourage the learning of rehabilitation techniques used by therapists and to improve the modification of parental beliefs. Those factors result to be important in promoting the full development of the child's potentialities. The intervention was also done to evaluate the anxiety-depressive states of the parents, and look for the variables that can affect the proper functioning of the family as an agent of change. Methodology and the realization procedures are described in detail in the article. Results confirm the utility of the intervention proposal.
\end{abstract}

Keywords Compliance, Rehabilitation, Children with intellectual disabilities, Parent-training, Parenting beliefs

\section{Introduction}

Studies on the compliance of the family with rehabilitative interventions in the context of intellectual disabilities are currently expanding. Research shows that compliance among parents and professionals involved in the intervention rehabilitation of disabled children leads to more effective and durable changes[1] and the experience of those who work in the field of rehabilitation confirms that, with the active collaboration of parents, interventions produce better results in the child, in terms of the consolidation of generalization of learning.

The interest in this problem, known as family-centered care, was born in the $60 \mathrm{~s}$, when the importance of the role of the family in the rehabilitation process was realized. Thus, require that the values, preferences, priorities and needs of the family are taken into consideration when designing and implementing the interventions[2].

Since then there have been numerous studies that have shown that the most effective way to improve compliance and rehabilitative intervention of family members is to understand their motivations and expectations.

It is true that the beliefs and goals of parents on the disorders of children with disabilities can sometimes be very different from those of health professionals[3]. It was also shown that the lack of collaboration between parents

* Corresponding author:

azampino@unime.it (Anna Zampino)

Published online at http://journal.sapub.org/edu

Copyright $(\mathcal{C}$ year Scientific \& Academic Publishing. All Rights Reserved and professionals in the selection and implementation of rehabilitation may be a contributing factor that can seriously compromise the effectiveness of treatment needed to promote personal empowerment, participation and better functioning equipment[4].

The element that most favours the strengthening of the compliance of the family seems to be the active involvement of parents in the rehabilitation project, from design to implementation. An educational intervention or rehabilitation that requires commitment and perseverance and duration could in fact be perceived as coercive, if a set of practices taxes the caregiver of the disabled person[5]. It furnishes the opportunity for parents to be put to the test. On one hand providing them with correct information on diseases and treatments, and on the other enhancing the awareness of their function and of the acquisition of self-regulation and monitoring strategies on the basis of adequate management of educational requirements, which can range from ordinary to particularly problematic[6].

In recent decades, it has also been shown that the informational and educational support provided to families with a child with disabilities assumes a crucial importance in the outcome of the interventions, because it produces positive results in terms of improving the functioning of individual and family effective interactions on the basis of acquired knowledge and skills, strengthening parental roles and in stress reduction[7].

Compared to the latter area, a number of studies that have analysed the problems and processes of normalization of families of children with disabilities have shown that the stress of the parents significantly correlated not only with 
the degree of functional impairment of the child and the severity of the syndrome, even (in reverse video) with the level of cohesion intra and inter-parental and with the degree of perceived support, both within the family and in a social context[8]. Some studies, in analysing the levels of stress in families with children with different types of intellectual disability, suggest that the stress of the parents is correlated with the problematic behavior and with the degree of functional impairment related to the syndrome of the child. These families are subject to a high psychological vulnerability, as being a parent of a disabled child carries the risk of isolation and self-isolation from the social context, such as feelings of disappointment, insecurity, fear and anxiety and depressive symptoms[9].

Dall'Aglio[10] notes, however, that the presence of the necessary cognitive and emotional resources in the family affects the "diversity of routes adaptive" system that each family can take. The acquisition or enhancement of these resources can indeed help to improve the affective climate and relationships within the family, with significant effects on marital satisfaction and psychosocial development of children[11]. Conversely, in families where there is not an adequate process of adaptation to disability, communication between parents remains largely centred on issues related to the syndrome and the problems of the child are neglected, the marital relationship becomes compromised, with inevitable negative consequences on the evolution of the family system as a whole[11;12].

In light of the experiences of the various critical moments that parents of a child with disabilities face over the life cycle, thus shows the need to design and initiate interventions to support a responsible, balanced and competent parenthood. The emotional and educational support functions are designed to allow parents to be active agents in promoting their well being and that of their children[13].

It is recognized in literature that the involvement of the family appears to be essential in promoting the full development of the child's potentialities[14]. This involvement must, however, entail a careful analysis of the psychological conditions of the parents and the emotional affective variables that can positively or negatively affect the proper functioning of the family as an agent of change. Furthermore, the evaluation of anxiety-depressive states is important, where there is the presence of a clinically significant symptomatology; the training intervention may not be advised[11].

Krauss et al.[15] have in fact shown that in some cases, participation may even be negative for the parent and produce a voltage increase and a decline in personal interactions and social relationships[5].

It is clear that dysfunctional evolution of the adaptation process to the issues produced by the child's disability may affect the process of the entire system and have an impact on the effectiveness of rehabilitation interventions. It is essential, therefore, that the rehabilitation team work in synergy with the family, which must be informed about the various forms of treatment, possible interventions, and involving them in all decisions that affect the rehabilitation process of the child[16].

During the training, the sharing of objectives, the means of implementation of the individual project and need to focus on the overall needs of the child should also be included. This type of intervention, that is part of parents' education, also provides for the promotion of personal and parental empowerment, in fact, it can be regarded as an active agent of progress, (albeit minimal and slow). This can help to change the condition of psychosocial distress and increase the feeling of well-being. The acquisition of stability and consistency also makes more effective therapeutic intervention, allowing the child to recognize their family environment as an educational setting[8].

The main objective of this research was to implement a training program to promote compliance during the rehabilitation intervention in parents of children with intellectual disabilities.

In particular, it is composed of:

a) stimulating the observational ability of the parents in changing the assessment made on the behavior of their children. The goal was to teach them how to discriminate between dysfunctional behaviors related to educational practices and those related to disabilities, thus leading to a change in their beliefs;

b) providing them with the basic knowledge concerning rehabilitation techniques used by professionals, in order to better manage their children's education and assessing the reduction of errors committed due to the parents' education;

c) Assessing the extent to which greater awareness education could foster communication between the spouses;

d) Verifying whether a greater awareness of management education could help reduce levels of anxiety and depression.

\section{Method}

\subsection{Participants}

In the study, 10 pairs of parents (socio-cultural middle class) with children between 1 and 8 years participated. Parents were contacted from various rehabilitation facilities in the territory of Messina. They had been informed about the path of rehabilitation and the cognitive enhancement of their children, but in turn had only sporadic meetings with professionals and their level of participation was poor.

The decision to engage in a parent training group was born from the need to motivate them to participate more actively in the therapeutic process in order to promote the generalization and maintenance of skills learned by children within the family setting.

\subsection{Instruments and Procedure}

The research was carried out in 3 phases: a phase of pre-training, aimed at the assessment of the initial training 
and post-training phase, in order to monitor the effects of the intervention on parents.

\subsubsection{Assessment}

In the pre-training phase assessment was carried out by individual interviews with couples, a questionnaire on the socio-demographic characteristics of the family and other assessment tools. In particular, the following were used a checklist to verify the parental perception of the child's behavior, a behavioral scale on educational methods used by parents and two self-assessment questionnaires: one on the symptoms of anxiety-depressive and the other on the communication dynamics of the couple.

During the interviews, the parents were informed about the functional evaluation carried out by the team in order to establish the rehabilitation project. The awareness of parents regarding the condition of the child and the interventions undertaken was gauged. The gaps in the knowledge, the erroneous beliefs and the attitudes of adherence to interventions, the motivation for collaboration with therapists and educational practices put in place in the family context were identified.

Checklist for the assessment of the child's behaviors, consisting of 16 items, detects, through the evaluation of parents, dysfunctional behaviors of the child in the following areas: personal autonomy (eg, "You wash and dress yourself"), interaction behaviors (eg, "He contributes to simple requests made by the mother") and leisure (e.g. Play alone"). The ability to answer on the 5-point Likert scale (answers being from never to always).

The checklist for assessing the behavior of the parent consists of 16 items that describe the behavior of the child and the ability to measure the behavioral responses of the parent. The answer mode is multiple choices and includes five possible answers to each of which was assigned a score from 0 to 5 according to criteria of adequacy defined on the basis of the principles of applied behavior analysis to education. The response categories and the allocation of their scores were selected and calibrated by the psychologists' training on the cognitive-behavioral approach.

CDQ (IPAT Depression Scale)[17] is a self-report questionnaire consists of 40 statements with three answer choices that evaluate aspects of depressive and anxious manifestations of parents.

POC Parent-Offspring Communication-Italian version is a Self-Assessment Questionnaire pair communication[18; 19]. The instrument consists of 20 items that explore the perception of communication between partners. The ability to answer the 5-point Likert scale (answers being from never to always); (eg, "I can say what I think about my wife / husband without feeling restricted or in distress").

On the basis of the indications obtained from the initial assessment, a parent training group was formed.

\subsubsection{Parent Training}

The training was divided into 10 weekly meetings, each lasting 2 hours, with the aim of sharing with parents the individualized educational program provided to children in outpatient treatment. Thus allowing a more rapid and effective generalization and a more stable maintenance of learning. While at the same time fostering communication and cooperation of torque, so as to reduce stress and improve the family atmosphere.

Specifically, the 1 st meeting was devoted to integrating the group, the discussion of common problems, the presentation of the course, the definition of the objectives and expected results, and the underlining if the importance of the participation of both parents.

At the 2nd meeting: information on disability was provided; how the role that environmental contingencies and specifically educational practices play in the genesis and maintenance of the child's behaviors; discussion of the dysfunctional beliefs of the participants.

During the 3rd meeting, the objectives and methods of intervention of rehabilitation treatments, of which children took part, were explained.

Then the 4th and 5th meetings were held for systematic observation of behavior and the principles of functional analysis. The functional value of some of the problematic behaviors detected was also highlighted.

At the 6th, 7th, 8th meetings, the intervention techniques that promote the acquisition of skills and techniques that reduce the emission of problem behaviors were presented. Parents were, therefore, involved in practical activities, such as modeling and role playing on the application of the techniques presented.

After each meeting, a reminder of the key points of each unit and "tasks" were provided as a homework assignment aimed at practicing what they learned in the group meetings. The monitoring sheets completed during the week were analysed and discussed at the beginning of each session.

The 9th and 10th meetings were devoted to practical exercises designed to test the generalization of knowledge and skills learned from the new situations. Finally, group discussions were held, relating to the questioning of beliefs found in the initial phase of training.

The training was conducted with an interactive approach. The transmission of the content was aimed at encouraging comparisons between couples and having them share their own experiences with the help of the conductors.

The contents of the training were selected not only to transmit knowledge but also skills to the family. In particular, much work was done on the understanding and use of functional analysis. Parents were led to observe what happens before an issuing behavior and to reflect on the role of antecedents. Having been guided to understand the relationship with the behavior shown by the child and what happens after it, in terms of parenting practices, led them to reflect on the short-and long-term behavior of their child. Exercises were carried out during the training sessions and parents were assigned homework to be done between sessions. Getting the parents used to engaging at home was very important because it was aimed at using what they 
learned in the training while assuming the responsibility in regards to the consolidation of what the children learned during the rehabilitative treatment. So, for example, parents were given observation cards and asked to look at a house, the antecedents and consequences of a target behavior. During the preparation session for the task, parents were encouraged to describe the behavior in operational terms in order to facilitate the detection procedure. This way of working has enabled us to make parents more responsible in the management of behavioral problems.

The systematic observation and teaching programs of reinforcement also allowed the teaching of new skills. During the sessions, it was identified in where the child was competent in a particular functional area. In the application of the task analysis, parents were led to understand the skills needed to promote and draw up a program where the goal, the steps, the techniques used and the time were defined. Through shaping, for example, the gradual improvement of the desired behavior was promoted, starting from an initial situation far from that desired. The processors' learning was achieved more quickly with the integration of the modeling or the use of prompts. Another aspect that has contributed to the effectiveness of the intervention was the use of video, giving us the opportunity to really see the progress of the participants and in turn monitor the strategies implemented.

The highlight of the training was that the transmission of expertise intervened on investigation and modification of dysfunctional beliefs. Many of the participants attributed the problem behaviors of their children to the disease and believed that it was impossible to take action and change them. The understanding of the mechanisms underlying behavior, learning strategies, behavior modification resulted in changes in the distorted beliefs of caregivers, promoting self-efficacy and the willingness to cooperate with therapists because now the parents felt they could bring about change. The work on the identification and modification of dysfunctional thoughts was carried out with the aid of data sheets and operational conditions, which made it possible to detect the situation, thought, emotion and behavior accordingly. Parents were asked to describe a situation regarding the management of their child during fits of emotions (e.g. frustration). We analyzed the thoughts related to mood and tried to replace them with useful thoughts and proposals. Everything was recorded on a worksheet with five columns and parents were free to share with the group their findings.

The components of the training, therefore, have been a formative part of the transmission of skills, behavior modification techniques, functional analysis or dysfunctional beliefs modification. This structure of the protocol was designed to make parents responsible, motivated and able to work with the professionals involved in the care of their child.

\subsubsection{Post-Training}

Completed the training, tools administered in the assessment phase were readministered in order to check for any changes.

\section{Results and Discussions}

The processing of data in order to evaluate the effectiveness of the intervention was carried out through the analysis of the detected changes in the fathers and mothers by comparing the pre-and post-training.

For greater statistical validity it appropriate to transform the raw scores into the arcsine formula of Freeman and Tukey[20]. Tables 1 and 2 shows the mean (M) and standard deviations (SD) of the scores obtained by mothers and fathers in all dimensions measured in pre and post-training.

Table 1. Means and standard deviations of the scores obtained from arcsine formula of the parents' questionnaires before and after the training

\begin{tabular}{|c|c|c|c|c|c|c|c|}
\hline \multirow[b]{2}{*}{ Parent } & & \multicolumn{2}{|c|}{$\begin{array}{l}\text { Parents } \\
\text { believes }\end{array}$} & \multicolumn{2}{|c|}{$\begin{array}{c}\text { Parents } \\
\text { behavior }\end{array}$} & \multicolumn{2}{|c|}{ Communication } \\
\hline & & Pre & Post & Pre & Post & Pre & Post \\
\hline \multirow{2}{*}{ Mother } & M & .84 & .68 & .96 & .90 & .64 & .54 \\
\hline & $\mathrm{SD}$ & .26 & .33 & .15 & .35 & .18 & .23 \\
\hline \multirow{2}{*}{ Father } & $\mathrm{M}$ & .89 & .68 & .88 & .86 & .50 & .47 \\
\hline & SD & .23 & .32 & .19 & .33 & .19 & .21 \\
\hline
\end{tabular}

Table 2. Means and standard deviations of the scores obtained from arcsine formula of the parents' questionnaires before and after the training

\begin{tabular}{cccccc}
\hline & & \multicolumn{2}{c}{ Anxiety } & \multicolumn{2}{c}{$\begin{array}{c}\text { Depressive } \\
\text { symptoms }\end{array}$} \\
\hline Parent & & Pre & Post & Pre & Post \\
\hline \multirow{2}{*}{ Mother } & $\mathrm{M}$ & .77 & .71 & .76 & .64 \\
& $\mathrm{SD}$ & .15 & .31 & .18 & .31 \\
\hline \multirow{2}{*}{ Father } & $\mathrm{M}$ & .59 & .54 & .48 & .43 \\
& $\mathrm{SD}$ & .07 & .21 & .27 & .16 \\
\hline
\end{tabular}

For the comparison between the scores obtained from the mothers and fathers, it was considered appropriate to use the non-parametric test by Mann and Whitney[21], and to analyse the differences between each one, Wilcoxon's pre-and post-training test was used[22].

As you can see in Figure 1, both parents assess their child's behavior less negatively in post training. This finding was also confirmed by simple comparisons made between the pre-and post-training.

There have, in fact, been detected statistically significant differences in the assessment of parental behavior emitted by the children. In the pre-training phase, parents evaluated in a negative way the behaviors adopted by children while in post-training there is a significant reduction in the perception of problematic behaviors reported by both parents in their children $[Z=2.49 ; p<.01]$ and their mothers $[Z=2.31 ; p<.01]$.

Looking at the Figure 2, which shows the mean scores on the behavior of the parents, we see a reduction in the number of errors committed due to their way of educating. 
In the pre-training, mothers tend to commit more errors on educating than fathers $[Z=2.25 ; \mathrm{p}<.01]$. These differences between the parents are not, however, detected immediately after training $[\mathrm{Z}=.53 ; \mathrm{p}=.6]$. Though mothers, when in comparing the errors in the pre-and post-educational training, seem to have less difficulty in implementing the educational choices $[Z=1.98 ; \mathrm{p}<.05]$.

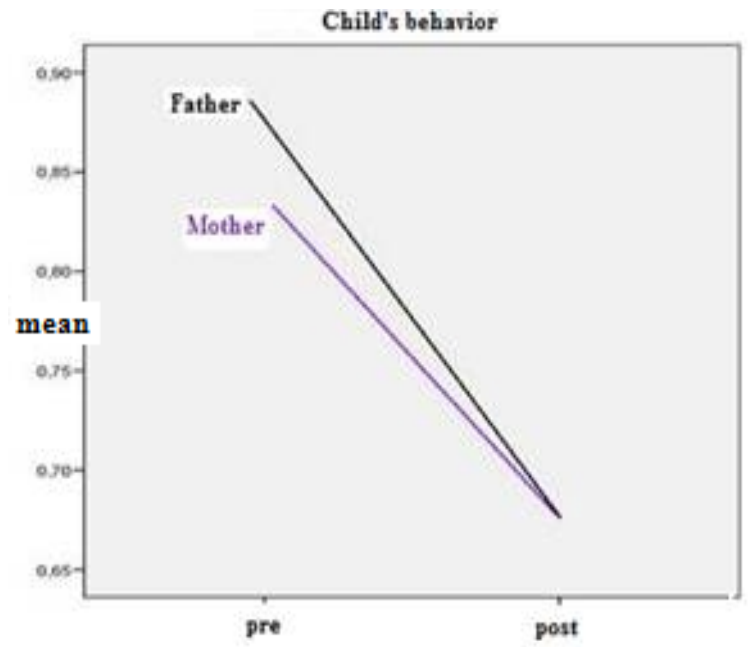

Figure 1. Graphical representation of the perception of parents about the inappropriate behavior of the children expressed during the pre-and post-training

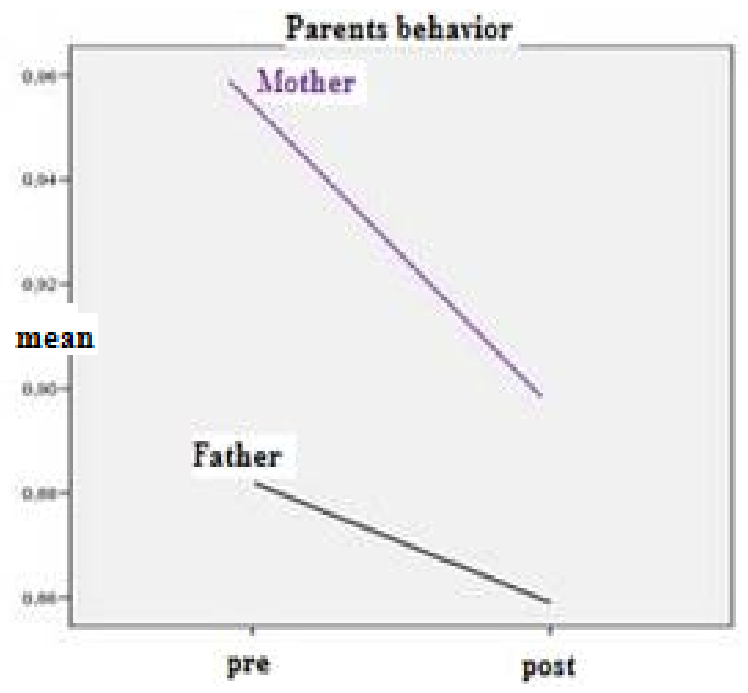

Figure 2. Graphical representation of the average number of errors committed by parents during the pre-and post-training

A further dimension taken into consideration is the communication of torque. Analysis of the data showed no significant differences between parents in pre-training $[\mathrm{Z}=1.28 ; \mathrm{p}=.19]$, and in post-training $[\mathrm{Z}=.98 ; \mathrm{p}=.32]$.

However, we detect an average reduction of errors in the communication of the couples. Training does not seem to have made a significant impact. In fact, the simple comparisons made between pre-and post-training, confirm that the number of errors is stable in the mothers $[Z=1.60$; $\mathrm{p}=.11]$, both fathers $[\mathrm{Z}=1.07 ; \mathrm{p}=.26]$.
The last two variables considered are the presence of anxiety and depressive symptoms (Figure 3-4).

With regard to anxiety levels, emerging as early as the pre-training, there is a substantial difference between fathers and mothers. In fact, in the latter there seems to be present a greater number of anxiety symptoms than the fathers $[Z=3.34$; $\mathrm{p}<.001]$. In post-training, however, it seems that these differences tend to reverse $[\mathrm{Z}=1.06 ; \mathrm{p}=.06]$.

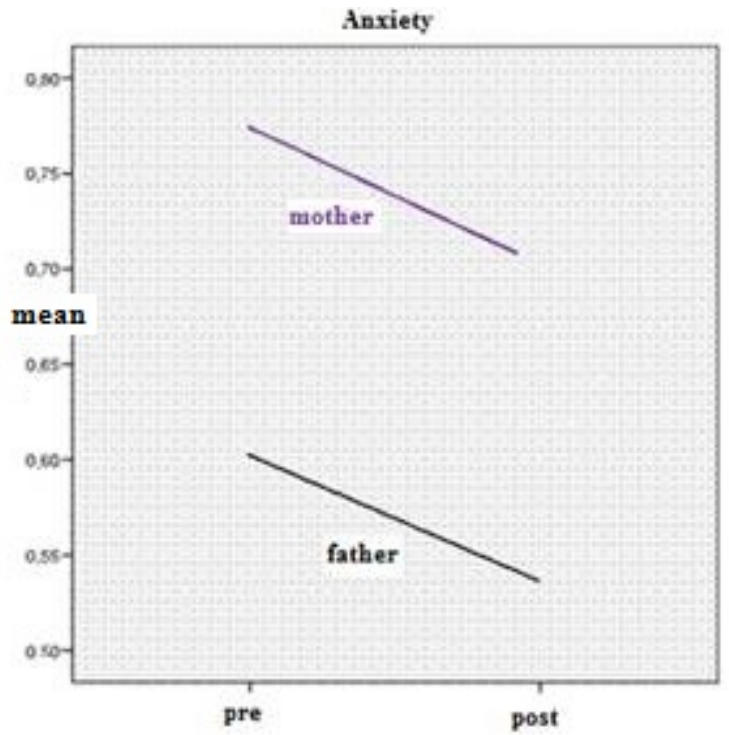

Figure 3. Graphical representation of the average score relative to the levels of anxiety expressed by parents during the pre-and post-training

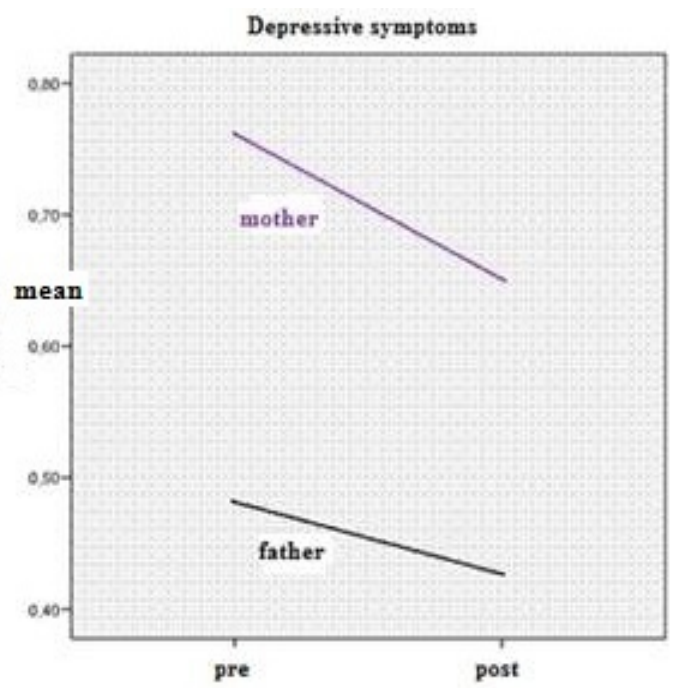

Figure 4. Graphical representation of the average score relative to the levels of depressive symptoms expressed by parents during the pre-and post-training

Similarly, the mothers in the pre-training have more depressive symptoms than the fathers $[\mathrm{Z}=2.31 ; \mathrm{p}<.02]$, but different levels of anxiety. These differences are maintained even in post- training $[Z=2.051 ; \mathrm{p}<.05]$.

There are significant differences between depressive symptoms expressed by mothers $[Z=1.12 ; p=.26]$ and fathers $[\mathrm{Z}=.42 ; \mathrm{p}=.67]$ comparing the pre-and post-training. 
Based on these results, we are able to identify which factors can explain the change in positive terms, the perception of parental behavior of the child, found in the post-training. In particular, through the analysis of linear regression, we tried to identify which factors best correlate the change in the assessment of dysfunctional behavior of their children. The analysis of the data seems to confirm the hypothesis that the evaluation of the dysfunctional behavior of the child is strongly influenced by the number of errors committed by the parents $[F(4.15)=3.92 ; p=.02 ; \beta=.89]$.

\section{Conclusions}

The objective of this study was the design and implementation of a training session for parents of children with intellectual disabilities. It was aimed at sharing with the parents an individualized educational plan provided for the children in outpatient treatment. The training was intended to encourage the learning of rehabilitation techniques used by therapists, so that parents could also apply them in different contexts of everyday life. The encouraged use of management education of children in the family would, in fact, maximizes the positive outcomes of rehabilitation. The training was intended to modify also the dysfunctional beliefs, understood in terms of assessing the conduct of the children, rather than being related to disability, is closely related to parental educational practices. The modification of parenting beliefs is crucial, as this is the basis of the awareness of the importance of their role in the adaptation of the child to his environment and the containment of problematic behaviors.

The proposal of a parent training intervention structured on the basis of these premises is extensively documented in the literature $[5 ; 6 ; 8]$ and on the detection of the real needs and the skills possessed by the participants. After the carrying out of the assessment, there was an effective response to the need to support families who are faced with the reorganization of the family system and special educational needs.

Analysis of the results showed that between the pre and post-training there are significant differences in the assessment of conduct issued by their children. That is, both parents in post-training perceive such behaviors significantly more positively. The problem behaviors exhibited by a child with a disability, if not properly managed by an appropriate and effective parenting, tend to crystallize in behaviors and in maladaptive relational types. Indeed, the development and operation of the child are governed by the laws of learning and adequate training in this area is essential to the achievement of positive results for the individual project and may affect relationships and the quality of the climate in the family system[6]. Based on this premise, then, the perception of a change in the behavior of the child seems to be explained as a result of the acquisition of parental observation skills and greater competence in the use of techniques aimed at increasing adaptive behaviors.
Compared to the behavior of parents, what emerged from the data in the pre-training, is that parents commit numerous errors in educating their children, especially mothers. Confirming what had been stated in the literature[11], it seems that mothers more than fathers are committed to the care and education of the child. The greater number of behavioral errors committed by mothers may be related to an overload of work which is conceivable to be one of the factors that affects the levels of perceived stress. The difficulties encountered by parents in the daily management of children can affect their personal perception of competence. In fact, everyday problems in the management of the child may be perceived by parents, as an expression of his inability or inadequacy in meeting the needs of the child.

In the post-training, however, the differences between mothers and fathers cancels out, and both tend to make fewer mistakes, especially mothers. Probably this was achieved when given correct information on the genesis of such behavior and the acquisition of skills in the use of behavioral modification techniques, leading to the improvement of management skills parenting. As demonstrated by the data collected, the parents have learned to understand the functional value of the dysfunctional behaviors, the antecedents to identify and understand the reinforcing effect of the environmental consequences and to modify such contingencies.

Compared with the figure on the change in perception of the communication pair, the intervention did not change the obvious communication errors that are confirmed stable in the post-training. Nevertheless, one must keep in mind that this type of intervention was not aimed at improving communication and cooperation between the couple.

With regard to the data on the levels of anxiety and depression, it appears that mothers have, in the pre-training, high levels of anxiety, to a significantly greater extent than fathers. In post-training this value decreases probably because the assessment of the behavior of the parents of the child is more realistic, and the acquisition of more educational skills modulates anxiety in relation to management education.

The levels of depression found in the pre-training, even in the standard, highlight the situation of impasse experienced by parents, especially mothers. In the post, the reduction of these indices is related to the perception of increased competence experienced by the parent. Making the parent more competent in handling requests from educational / facilitation had in fact improved indirectly the adaptation on the emotional-affective. The analysis of the data, therefore, shows a significant reduction of the levels of anxiety and depression.

The results seem to confirm the effectiveness of the proposed approach and support aimed, in the short term, to remove attitudes such as non-acceptance of disability, under or over-evaluation of deficits, feelings of inadequacy and lack of confidence in the rehabilitation. The training provided, in fact, the teaching techniques of behavior 
modification, the same used by rehabilitation professionals and it is plausible to assume that this will lead to increased understanding by parents of individualized rehabilitation plan and long-term compliance.

The search, however, presents some limitations: the small number of the sample does not permit the generalization of the results and the absence of follow-up does not allow ascertaining with certainty the effectiveness of the intervention. In addition, because the project does not act on the entire family system the follow-up would need to assess whether the techniques learned have been generalized to the whole family context.

In this work, however, presented some of the preliminary data collected in the larger study that is taking place on the psychological aspects related to parental compliance with respect to the rehabilitation intervention and the factors that appear to influence the perception of the behavior of the child.

The data collected is already indicative of a trend that is thought to be supported by further processing and suggest interesting potential applications. In particular, it would be interesting to investigate the relationship between parental compliance and additional dimensions such as the degree of cooperation within the marriage and the perception of support received from the partner.

This study gives us, therefore, evidence in support of the importance of carrying out of psycho educational support to families. Model of parenting skills, increased effective family interactions, increased parental compliance to the rehabilitation intervention, identifying the psychological resources and modulate the states of parental distress are, therefore, in our opinion, the goals that a training program should work towards. It is necessary, finally, to encourage the rehabilitation team to work in collaboration with parents, children, teachers and other health professionals.

\section{REFERENCES}

[1] Lucyshyn, J.M., Horner, R.H., Dunlap, G., Albin, R.W., Ben, K.R., "Positive behavior support with families", in J.M. Lucyshyn, G. Dunlap, R.W. Albin, Families and positive behavior support: Addressing problem behavior in family contexts, MD: Paul H., Baltimore, 2002.

[2] Benedetto L., Ingrassia M., "Parenting. Psicologia dei legami familiari”, Carocci Editore, Roma, 2010.

[3] Rasaratnam R, Crouch K., Regan A., "Attitude to medication of parents/primary carers of people with ID", Journal of Intellectual Disability Research, no.48, pp.754-763, 2004.

[4] Glaun D. E., Cole K. E., Reddihough D.S., "Six month follow-up: the crucial test of multidisciplinary developmental assessment", Child: Care, Health and Developmental, vol.24, no.6, pp.457-472, 1998.

[5] Zanobini M., Usai M.C., "Psicologia della disabilità e della riabilitazione. I soggetti, le relazioni, i contesti in prospettiva evolutiva”, Franco Angeli, Milano, 2008.
[6] Larcan R., "Handicap e famiglia: problemi e prospettive, in Zampino A., Il Ritardo Mentale, Ed. Pungitopo, Patti, 2000.

[7] Dempsey I., Keen D., Pennell D., O’Reilly J., Neilands J., "Parent stress, parenting competence and family-centered support to young children with an intellectual or developmental disability", Research in Developmental Disabilities, no.30, pp.558-566, 2009.

[8] Larcan R., Oliva P., Sorrenti L., "Interventi psicologici sulla famiglia", Piccin, Padova, 2008.

[9] Vianello R., Lanfranchi S., Moalli E., "La sindrome di Down. Sviluppo psicologico e integrazione dalla nascita all'età senile", Edizioni Junior, Bergamo, 2006.

[10] Dall'Aglio E., "Handicap e famiglia", in Handicap e Collasso Familiare. Quaderni di Psicoterapia Infantile, no.29, Borla, Roma, 1994.

[11] Zanobini M., Manetti M., Usai M.C., "La famiglia di fronte alla disabilità", Edizioni Erickson, Trento, 2002.

[12] Soresi S., "Psicologia delle disabilità", Il Mulino, Bologna, 2007.

[13] Zampino A., "La famiglia accanto al bambino diversamente abile", in Convegno ECM: La famiglia nella realtà della malattia. Commissione di Pastorale Sanitaria A.U.S.L n.5 di Messina and P.O. "Barone Romeo", Patti, 2008.

[14] Lerman C.D., Swiezy N., Perkins-Parks S., Roane H.S., "Skill acquisition in parents of children with developmental disabilities: interaction between skill type and instructional format", Research in Developmental Disabilities, no.21, pp.183-196, 2000.

[15] Krauss R. M.. "Nonverbal behaviors à la carte" (review of Robert S. Feldman \& Bernard Rimé, Fundamentals of nonverbal behavior, Contemporary Psychology, no. 38, pp. 507-508, 1993.

[16] Becchi M. A., Carulli N., "Le basi scientifiche dell'approccio bio-psico-sociale. Indicazione per l'acquisizione delle competenze mediche appropriate", Internal and Emergency Medicine, vol.4, no.3, pp.1-8, 2009.

[17] Novaga M., Pedon A., "Adattamento italiano del Questionario di autovalutazione C.D.Q. (IPAT Depression Scale) of Krug S.E., Laughling J.E, CDQ (Ipat Depression Scale), Organizzazioni Speciali Giunti, Firenze, 1979.

[18] Barnes H., Olson D., "Parent-adolescent communication", in Olson D.H., McCubbin H.I., Barnes H., Larsen A., Muxen M. e Wilson M., Family inventories, St. Paul: Family Social Science, University of Minnesota, pp. 33-48, 1982.

[19] Lanz M., "Parent-Offspring Communication Scale: applicazione ad un campione italiano", Bollettino di psicologia applicata, no.224, pp.33-38, 1997.

[20] Freeman M.F., Tukey J.W., "Transformation related to angular and square root", Annuals of Mathematics and Statistics, no.21, pp.607-611, 1950.

[21] Mann H.B., Whitney D.R., "On test of whether one of two random variables is stochastically langer than the other", Annals of mathematical statistics, vol.18, no.1, pp.50-60, 1947.

[22] Wilcoxon F., "Individual comparison by ranking methods", Biometrics Bulletin, no.1, pp.80-83, 1945. 